\title{
Contribuições da Ciência da Informação para a Ciência das Redes
}

\author{
Gustavo Vasconcellos Cavalcante* \\ Mamede Lima-Marques**
}

\begin{abstract}
"As últimas descobertas científicas mostram que todas as formas de vida - desde as células mais primitivas até as sociedades humanas, suas empresas e Estados nacionais, até mesmo sua economia global - organizam-se segundo o mesmo padrão e os mesmos princípios básicos: o padrão em rede." Fritjof Capra (CAPRA, 2002)
\end{abstract}

\section{Resumo}

Se pudéssemos escolher uma palavra para resumir a sociedade do século XXI, esta palavra deveria ser "conectada". Nós crescemos sem perceber a imensa interligação de redes necessária para nosso moderno estilo de vida. Somente quando existem problemas no fornecimento de algumas destas facilidades é que começamos a perceber a existência de redes para: eletricidade, água, gás, TV à cabo, telefone, comunicação de dados, etc. Estas redes também nos permitem contatar praticamente qualquer pessoa no planeta. Durante a última década, diversas pesquisas foram feitas por pesquisadores de diversas áreas: Física, Ciência da Computação, Sociologia, Matemática, Ciência da Informação. Na época da escrita deste documento estamos participando do alvorecer de uma nova ciência - A "Ciência das Redes". Esta ciência, que por sua própria natureza já nasce com características transdisciplinares, vem procurar buscar respostas aos desafios do novo milênio. Neste artigo apresentaremos algumas contribuições oriundas da Ciência da Informação que estão sendo redescobertas para a consolidação da ainda nascente Ciência das Redes.

Palavras-chave: Redes. Ciência das Redes. Ciência da Informação. Redes Complexas.

Titulo: Contribuciones de la Ciencia de la Información para la Ciencia de las Redes.

\section{Resumen}

Si pudiéramos escoger una palabra para resumir la sociedad del siglo XXI, esa palabra debería ser "conectada". Crecemos sin darnos cuenta la inmensa interconexión de redes necesaria para

\footnotetext{
* Doutorando em Ciência da Informação no Programa de Pós-graduação em Ciência da Informação da Universidade de Brasília. gustavoc@unb.br.

** Professor Titular do Departamento de Ciência da Informação da UnB., Pós-Doutorado em Lógica Aplicada à Ciência da Computação pelo Centro de Lógica, Epistemologia e História da Ciência, UNICAMP, doutor e mestre em Ciência da Computação pelo Institut de Recherche en Informatique de Toulouse, Université Paul Sabatier, Toulouse III, França. mamede@unb.br
} 
nuestro moderno estilo de vida. Solamente cuando existen dificultades en el suministro de algunos de estos servicios comenzamos a percibir la existencia de redes para: electricidad, agua, gas, televisión por cable, teléfono, comunicación de datos, etc. Estas redes también nos permiten entrar en contacto prácticamente con cualquier persona del planeta. Durante la última década fueron realizadas diversas investigaciones en diversas áreas como: Física, Ciencia de la Computación, Sociología, Matemática y Ciencia de la información. En el momento de la redacción de este documento estamos participando del surgimiento de una nueva ciencia - La Ciencia de las Redes. Esta ciencia, que por su propia naturaleza ya nace con características transdisciplinares, procura buscar respuestas a los desafíos del nuevo milenio. En este artículo presentamos algunas contribuciones originadas en la ciencia de la información que están siendo redescubiertas para la consolidación de la naciente ciencia de las redes.

Palabras Clave: Redes. Ciencia de las Redes. Ciencia de la Información. Redes Complexas.

Title: Contributions of Information Science to Network Science

\begin{abstract}
If there is one word to describe society in the early twenty-first century, this word should be "connected". We have grown up without realizing the enormous interconnection of networks for our modern lifestyle. Only when there are problems in the supply of electricity, water, gas, cable TV, telephone or data communication, we perceive the existence of networks. These networks allow us to contact anyone on the planet. During the last decade, there were several researches from different areas: Physics, Computer Science, Sociology, Mathematics and Information Science. Nowadays, we are participating in the dawn of a new science - "Network Science". This science has already born transdisciplinary. In this article we present some contributions from Information Science that are being rediscovered for the consolidation of the still nascent Network Science.
\end{abstract}

Keywords: Networks. Network Science. Information Science. Complex Networks.

\title{
1 Introdução
}

Se pudéssemos escolher uma palavra para resumir a sociedade do século XXI, esta palavra deveria ser "conectada" (APPLICATIONS, 2005). Nós crescemos sem perceber a imensa interligação de redes necessária para nosso moderno estilo de vida. Somente quando existem problemas no fornecimento de algumas destas facilidades é que começamos a perceber a existência de redes para: eletricidade, água, gás, TV a cabo, telefone, comunicação de dados, 
etc. As redes de comunicação e de dados, por exemplo, nos permitem contatar praticamente qualquer pessoa no planeta.

O termo "redes" pode ser utilizado em sentidos menos óbvios. A transmissão de uma determinada doença está diretamente relacionada à constituição da rede de conexão entre as pessoas. Os terroristas formam redes entre si com o objetivo de organizar um determinado atentado. Autores de um determinado ramo da ciência citam uns aos outros formando uma rede de citações. Organizações humanas formam redes ente si, possíveis de serem visualizadas em organogramas e em outros gráficos organizacionais. Quando vamos adquirir alguma mercadoria não pensamos na rede de distribuição necessária para entregar este item. Nosso cérebro é uma rede de alta complexidade constituída pela interligação de neurônios. Castells (2003) caracteriza a nossa sociedade atual como "A sociedade em rede".

Durante a última década, diversas pesquisas foram feitas por pesquisadores de diversas áreas, dentre elas: Física, Ciência da Computação, Sociologia, Matemática, Ciência da Informação para o melhor entendimento das estruturas em rede. $\mathrm{Na}$ época da escrita deste documento estamos participando do alvorecer de uma nova ciência - a "Ciência das Redes". Esta ciência, que por sua própria natureza já nasce com característica transdisciplinar ${ }^{1}$, vem procurar buscar respostas aos desafios do novo milênio.

A Ciência da Informação, pela sua própria natureza interdisciplinar e transdisciplinar, é um terreno fértil e acolhedor para pesquisas desta natureza. Saracevic (1995) afirma que a Ciência da Informação é interdisciplinar por natureza e a relação com outras disciplinas vem mudando constantemente; e além e acima da tecnologia, tem uma forte dimensão humana e social.

O tradicional Annual Review of Information Science \& Technology (ARIST) produzido pela American Society for Information Science \& Technology (ASIST) publicou na sua edição de 2007 um capítulo sobre a nascente ciência das redes (BORNER; SANYAL; VESPIGNANI, 2007), consolidando assim a Ciência da Informação como uma das ciências precursoras no desenvolvimento da Ciência das Redes.

Neste artigo apresentaremos algumas contribuições oriundas da Ciência da Informação que estão sendo redescobertas para a consolidação da ainda nascente ciência das redes.

\footnotetext{
${ }^{1}$ Neste trabalho é adotado a definição da Organization for Economic Co-Operation and Development (OECD). A pesquisa transdisciplinar refere-se a um processo onde existe convergência entre as disciplinas, acompanhada pela integração mútua das epistemologias disciplinares (MORILLO; BORDONS; GOMEZ, 2003).
} 


\section{Ciência das Redes}

O entendimento do complexo mundo que nos rodeia é uma tarefa das mais difíceis e princípios simples que capturem as características essenciais destes sistemas naturais complexos são sempre bem-vindos. Um destes princípios é a sua organização em rede onde constituintes de diversos elementos que interagem entre si. Na natureza existe uma infinidade de tais sistemas: pessoas e redes sociais, neurônios e cérebro, computadores e redes de telecomunicação, dentre outros (BORNHOLDT; SCHUSTER, 2003).

As redes são descritas como um conjunto de itens conectados entre si. Estes itens são chamados de vértices ou nós, e as conexões entre eles são chamadas de arestas. As redes podem ser formadas de átomos, moléculas, plantas, células, palavras, citações, roteadores da Internet, paginas web, etc. Na literatura matemática, redes também são chamadas de grafos. Na Figura 1 pode-se observar um exemplo de uma rede.

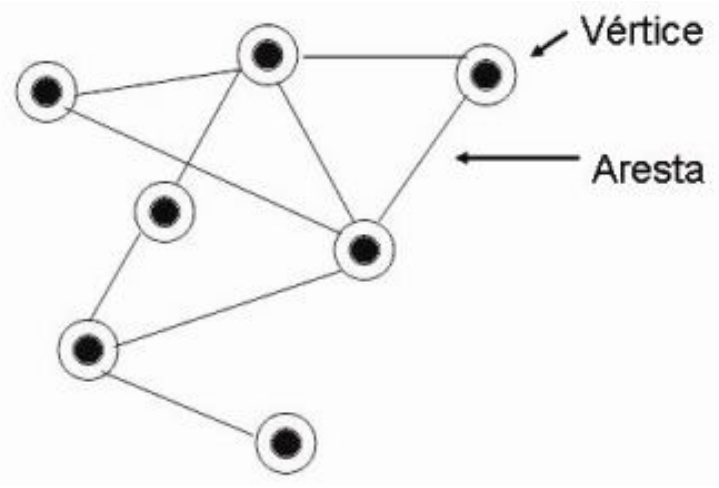

Figura 1: Exemplo de uma rede pequena com 7 vértices e 9 arestas

Redes, tais como a Internet, a World Wide Web, rede biológicas e redes sociais têm sido objetos de intensos estudos recentemente. Pesquisadores das mais diversas áreas têm encontrado uma grande variedade de sistemas que podem ser representados como redes e que existe muito a ser aprendido por meio do estudo destas redes.

É possível observar que, em grande parte das vezes, o estudo dos elementos constituintes de uma rede é insuficiente para explicar o seu comportamento. Existem variáveis importantes às ligações e às formas de construção da rede. Propriedades fundamentais da rede estão presentes em sua própria topologia, na descrição física ou geométrica das mesmas. Estes elementos são perdidos quando o foco deixa de ser a rede e passa a incidir apenas nos itens. Examinar apenas um neurônio não é o suficiente para descrever o cérebro, da mesma forma que a análise de um indivíduo ou 
computador não é suficiente para permitir conclusões amplas a respeito, respectivamente, das sociedades e da Internet (ANGELIS, 2005).

Esta característica apresentada pelas redes, na qual a observação das partes não é capaz de descrever o todo, limita as abordagens analíticas que tem como pressupostos a decomposição de um problema em componentes menores.

É possível observar que o conhecimento científico sempre procurou unidades mais simples para explicar a realidade. Isso levou-nos a descobertas fantásticas em várias áreas do conhecimento: a Biologia descobriu a célula, o gene e o DNA; a Física descobriu a molécula, o átomo e a partícula. Tudo o que não correspondesse ao esquema simplificador era abafado ou eliminado. De acordo com Fortin (2007), a desordem, o acaso e o singular foram deste modo afogados em concepções estatísticas ou puramente eliminados como resíduos e dejetos (isto é, como não científicos). Esta redução é claramente empobrecedora do conhecimento porque deixa de explorar parte considerável da realidade.

Cada vez mais, é possível perceber que nada acontece isoladamente. A maioria dos eventos e fenômenos estão conectados, causados pela interconexão de imenso número de peças neste complexo quebra-cabeça universal. Atualmente, cientistas de várias áreas do conhecimento têm descoberto uma que a complexidade possui uma arquitetura peculiar. Esta se descobrindo a importância das redes (BARABÁSI, 2003).

Praticamente todo sistema complexo pode ser pensado como uma rede. Átomos formam uma rede fazendo macromoléculas. Proteínas formam uma rede fazendo células. Células formam uma rede fazendo órgãos e corpos. Nós formamos uma rede construindo sociedades e assim por diante. Estas redes têm muitas características em comum da sua topologia ao seu dinamismo (CSERMELY, 2006).

As redes têm a singularidade de atuarem como estruturas emergentes, ou seja, próprias de sistemas complexos e dinâmicos (KLUVER; SCHMIDT, 1999). Em outras palavras, as redes revelam estruturas sociais (padrões de interação) que podem evoluir de forma não-linear e, portanto, produzir conseqüências imprevistas sobre determinado contexto. O importante é que essa ação emergente tem implicações nas macro e micro-dimensões, e a compreensão desse processo crítico nos aproxima muito mais da realidade cotidiana.

Nos últimos anos, um grupo diverso de cientistas, incluindo físicos, biólogos, matemáticos, sociólogos, cientistas da computação, dentre outros, vêm construindo um novo 
campo de pesquisa a teoria das redes ou a também chamada "Ciência das Redes" (BARABÁSI et al., 2002; WATTS, 2003). Este ramo científico foi impulsionado principalmente por:

a) pelos dados recentemente disponíveis de grandes redes do mundo real (estrutura molecular das redes do mundo real, estrutura da Internet, dentre outros);

b) Aumento do poder computacional para processamento de dados;

c) uma grande quantidade de pesquisas quantitativa na estrutura e dinâmica das redes (principalmente nos últimos 10 anos).

Trata-se de um tema multidisciplinar em que físicos, economistas, biólogos, sociólogos, engenheiros, cientistas de computação e psicólogos, dentre outros, têm se debruçado. A idéia principal por trás destes estudos refere-se ao fato de que redes tanto naturais (por exemplo, rede de células) como artificiais (como redes de relacionamento entre pessoas ou rede de citações em artigos científicos) possuem uma série de características em comum.

Esta nova ciência pode ser aplicada a praticamente todas do saber. As redes (sejam elas de computadores, células, pessoas, empresas ou moléculas) são o resultado de uma rede intricada de conexões. A vida é o produto da interação de uma complexa rede de moléculas dentro das células. A economia é uma rede complexa de empresas e consumidores. A sociedade é uma rede complexa de pessoas conectada por laços de família, amizade e trabalho. A Internet é uma teia complexa de computadores. Todos fazemos parte, queiramos ou não, de várias redes.

Antevendo a importância da ciência das redes o exército americano encomendou uma pesquisa ao National Research Counsil (APPLICATIONS, 2005), convocando a elite da comunidade científica americana em temas relacionados a redes, sobre a necessidade de uma ciência das redes e a resposta (de forma sintética) foi a seguinte:

a) As redes estão no núcleo da estrutura econômica, social e política do século XXI. A demanda por conhecimento estruturado para projetar, adquirir e operar redes é universal e cresce rapidamente. Investimentos na ciência das redes são uma prioridade nacional urgente e estratégica.

b) O conhecimento sobre a estrutura, a dinâmica e comportamento de redes de grande infraestrutura e redes sociais vitais ainda é primitivo. 
Segundo (BARABÁSI et al., 2002), as redes descrevem um grande número de sistemas na natureza e na sociedade e que está cada vez mais sendo reconhecido que a topologia e a evolução das redes reais são governadas por princípios robustos de organização.

Abre-se um campo de pesquisa empolgante e promissor em termos de aplicações nas mais diversas áreas.

\section{Contribuições da Ciência da Informação}

Dragulanescu (2003) afirma que um dos mais importantes fenômenos para a evolução da Ciência da Informação é a sua abertura a outras disciplinas como: Informática, Eletrônica, Telecomunicações, Linguística, Matemática, Psicologia, e Sociologia. Segundo este autor, a transgressão das fronteiras conduz a influências recíprocas e ao desenvolvimento de sinergias, que têm como consequiência o enriquecimento mútuo.

A Ciência da Informação vem colaborando de maneira significativa para o desenvolvimento da Ciência das Redes. O método de Análise de Redes Sociais, por exemplo, tem sido usado com sucesso em diversos trabalhos da área.

Na década de 60, com o avanço da Cientometria, uma substancial produção científica foi desenvolvida. Segundo Santos (2003), a Cientometria constitui-se em um método baseado em técnicas estatísticas, que tem como objetivo identificar e tratar as informações contidas nas publicações científicas e técnicas, disponíveis nos sistemas de informação. Entre os temas estudados pela Ciência da Informação está a produção científica, produto da comunicação científica que possibilita a análise do nível de desenvolvimento de uma determinada área do conhecimento humano. Para atingir este objetivo utiliza as disciplinas métricas (do grego metron), entre elas a Bibliometria e, mais recentemente, à Cientometria e a Informetria. Por meio dessas análises, é possível mapear o desenvolvimento da ciência, conhecer as relações entre pesquisadores, identificar núcleos de publicação de uma área, bem como a frente de pesquisa de um determinado campo (MACHADO, 2007).

Derek John de Solla Price (1922-1983), físico, e posteriormente um cientista da informação e historiador da ciência é considerado o pai da Cientometria. Ele descreveu em 1965 provavelmente o primeiro exemplo do que seria posteriormente chamado de rede livre de escala (scale-free network) ${ }^{2}$.

\footnotetext{
${ }^{2}$ Em uma rede livre de escala, alguns nós se encontram altamente conectados, ou seja, possuem um grande número de
} 
Ele estava estudando uma rede de citações entre artigos científicos e observou que os números de vezes em que um artigo é citado e o numero de artigos que um artigo cita tem uma distribuição em forma de lei de potência (SOLLA PRICE, 1965). Segundo Newman (2003), aparentemente intrigado com o aparecimento destas leis de potência, ele publicou outro artigo intitulado A General Theory of Bibliometric and Other Cumulative Advantage Processes (SOLLA PRICE, 1976), no qual ele oferece uma explicação para essas leis de potência. Solla Price foi talvez o primeiro a discutir especificamente a vantagem cumulativa no contexto das redes. A sua idéia era que a taxa com que um artigo inicia a receber novas citações deve ser proporcional ao número das que já tem. O mesmo argumento pode também ser aplicado a outras redes. As idéias de Price foram baseadas nos trabalhos desenvolvidos nos anos 50 pelo polímata Hebert Simon (1916-2001

Hebert Simon foi um pesquisador nas áreas da Psicologia Cognitiva, Informática, Administração Pública, Sociologia Econômica, e Filosofia. Simon (1955) foi um pioneiro ao explicar a ocorrência da distribuição livre de escala estudando a distribuição riqueza. Simon demonstrou que o fenômeno das leis de potência aparece quando o fenômeno "Rico fica mais rico" também conhecido como "Efeito Mateus" ${ }^{3}$ ocorre. Solla Price chamou esta característica de crescimento das redes de Vantagem Cumulativa (cumulative advantage). Cerca de 23 anos depois, Barabási e Albert (1999) apresentaram este fenômeno chamando de Acoplamento Preferencial (preferential attachment).

A grande contribuição do trabalho de Price foi aproveitar as idéias de Simon aplicando-as no contexto do crescimento de redes. Segundo Newman (2003), Price parece ter sido o pioneiro em discutir a vantagem cumulativa no contexto das redes, mas especificamente no contexto das redes de citações entre artigos científicos. De acordo com suas idéias, a taxa em

ligações com outros nós, enquanto o grau de conexão de quase todos os outros nós é bastante baixo. Isso implica que certos nós possuem uma quantidade enorme de conexões com outros nós, enquanto a maioria dos nós tem poucas conexões. Os nós mais visitados, denominados pólos de irradiação e convergência, podem ter centenas, milhares ou mesmo milhões de ligações. Nesse sentido, a rede parece não ter uma escala. Estas redes são denominadas livres de escala, pois mostram uma distribuição heterogênea dos graus dos nós, ou seja, não apresentam um grau médio típico. ${ }^{3} \mathrm{O}$ famoso efeito Mateus deve o seu nome a célebre parábola bíblica do senhor que chamou os seu servos, dando a um 5 talentos, a outro 2 e ao terceiro 1 talento e recomendando que os fizessem frutificar.O que recebeu 5, trabalhou e conseguiu outros 5. O que recebeu 2 agiu do mesmo modo e conseguiu 4. O que recebeu 1, com medo que o roubassem foi escondê-lo debaixo da terra. O senhor regressou, chamou os servos e pediu-lhes contas pelos talentos dados. O que tinha recebido 5 apresentou 10; o que tinha recebido 2 apresentou 4; o que recebera 1 apresentou-o e devolveu-o.

E então o senhor louvou os que tinham duplicado os talentos. E pegou no talento que tinha estado enterrado e ordenou:

"Tirai-lhe o talento e dai-o ao que tem dez. Porque, a todo aquele que tem, será dado mais, e terá em abundância. Mas ao que não tem, até o que tem lhe será tirado"(Mateus, 25, 28-29)(BÍBLIA, 1999). 
que um artigo científico recebe novas citações deve ser proporcional ao número de citações que ele já possui.

No final da década de 90, varias das idéias de Solla Price, foram redescobertas (aparentemente de forma independente) em outras áreas da ciência, como a Física, por exemplo, e publicadas com grande estardalhaço, como se fossem inéditas. Posteriormente descobriu-se que estas idéias já haviam sido publicadas em periódicos da área da Ciência da Informação, cerca de 30 anos antes.

Em 1984, Price recebeu postumamente o prêmio de pesquisa da Sociedade Americana para Ciência da Informação e Tecnologia pelas suas extraordinárias contribuições no campo da Ciência da Informação.

\section{Conclusão}

Neste artigo foi possível observar o envolvimento da Ciência da Informação com a nascente Ciência das Redes. Contribuições fundamentais para o desenvolvimento desta ciência foram publicadas inicialmente na área da Ciência da Informação. O primeiro trabalho científico publicado sobre redes livre de escala foi provavelmente a rede descrita por Price sobre citações entre artigos científicos (SOLLA PRICE, 1965).

O mecanismo da "vantagem cumulativa" proposto por Solla Price é atualmente amplamente aceito pela comunidade científica como a provável explicação para a distribuição em distribuição com o grau de lei de potência observada atualmente em uma ampla variedade de redes tais como: redes de citações científicas, a World Wide Web, a Internet, etc .

Por outro lado, os trabalhos de Solla Price são geralmente desconhecidos fora da comunidade da Ciência da Informação e o seu trabalho não recebeu o devido reconhecimento até ser redescoberto décadas mais tarde por outros pesquisadores.

Atualmente temos uma série de facilidades, inexistentes na época de Solla Price, como por exemplo, o extraordinário avanço do poder computacional e a disponibilidade de grandes volumes de dados para simulações computacionais. Estes avanços possibilitaram confirmar a validade das descobertas de Solla Price no contexto das citações entre pesquisadores e possibilitar a ampliação dos conceitos desenvolvidos por Solla Price para outros tipos de redes. 


\section{Referências}

ANGELIS, André Franceschi de. Tutorial - Redes Complexas. Disponível em http://kyatera.incubadora.fapesp.br/portal/research/tutorials/Tutorial_RedesComplexas_Lightways. pdf. Acessado em dezembro de 2005.

APPLICATIONS, National Research Council (U.S.). Committee on Network Science for Future Army Network Science, Committee on Network Science for Future Army Applications, National Research Council.. Washington:The National Academies Press, 2005.

BARABÁSI, Albert-Laszló. Linked : how everything is connected to everything else and what it means for business, science, and everyday life. New York: Plume, 2003.

BARABÁSI, AL et al. Evolution of the social network of scientific collaborations. Physica A: Statistical Mechanics and its Applications, Elsevier, v. 311, n. 3-4, p. 590-614, 2002.

BARABÁSI, A. L.; ALBERT, R. Emergence of scaling in random networks. Science,., v. 286, n. 5439, p. 509-512, Outubro 1999.

BÍBLIA. Bíblia Sagrada. São Paulo: Editora Ave Maria, 1999.

BORNER, Katy; SANYAL, Soma; VESPIGNANI, Alessandro. Network science. Annual Review Of Information Science And Technology, v. 41, p. 537-607, 2007.

BORNHOLDT, Stefan; SCHUSTER, Heinz Georg. Handbook of graphs and networks : from the genome to the internet. Primeira edição.New York: Wiley, 2003..

CAPRA, Fritjof. As conexões ocultas: ciência para uma vida sustentável. São Paulo: Editora Cultrix, 2002.

CASTELLS, M. A sociedade em rede - A era da informação economia, sociedade e cultura . São Paulo: Ed. Paz e Terra, 2003.

CSERMELY, Peter. Weak Links: Stabilizers of Complex Systems from Proteins to Social Networks (The Frontiers Collection). Berlim: Springer, 2006. 
DRAGULANESCU, Nicolae George, De nouveaux modeles pour les sciences de l'information ? Communication, CIFSIC. Bucarest, 2003. Disponível em <

http://archivesic.ccsd.cnrs.fr/sic_00000514.en.html>. Acesso em: Dezembro de 2008.

FORTIN, Robin. Compreender a Complexidade - Introdução a 0 Método de Edgar Morin. Lisboa - Portugal: Instituto Piaget - Coleção: Epistemologia e Sociedade, 2007.

KLUVER, Jürgen; SCHMIDT, Jorn. Topology, metric and dynamics of social systems. Journal of Artificial Societies and Social Simulation, v. 2, n. 3, 1999.

MACHADO, Raymundo das Neves. Scientometric analysis of bibliometric studies published in brazilian library and information science journals (1990-2005). Perspectivas em Ciência da Informação, Scielo, v. 12, p. 2 - 20, 122007

MORILLO, F.; BORDONS, M.; GOMEZ, I. Interdisciplinarity in science: a tentative typology of disciplines and research areas. Journal of the American Society for Information Science and Technology, v. 54, n. 13, p. 1237-1249, 2003.

NEWMAN, M. E. J. The structure and function of complex networks. SIAM Review, SIAM, v. 45, n. 2, p. 167-256, 2003.

SANTOS, R. N. M. dos. Indicadores estratégicos em ciência e tecnologia: refletindo a sua prática como dispositivo de inclusão/exclusão. Transinformação, p. 129-140, set./dez. (Edição Especial), Campinas: 2003.

SARACEVIC, Tefko. Interdisciplinary nature of Information Science. Ciência da Informação, v. 24 , n. 1,1995.

SIMON, Herbert A. On a class of skew distribution functions. Biometrika, v. 42, p. 425-440, 1955. SOLLA PRICE, Derek J. de. Networks of scientific papers. Science, v. 149, n. 3683, p. 510-515, 1965.

SOLLA PRICE, Derek de. A general theory of bibliometric and other cumulative advantage processes. Journal of American Society of Information Science, v. 27 (Sept-Oct), p. 292-306, 1976.

WATTS, Duncan J. Six degrees : the science of a connected age. Nova York: Norton, 2003. 